\title{
Identificaton of the Alarm and Sex Pheromones of the Leaf-Footed Bug, Leptoglossus zonatus (Heteroptera: Coreidae)
}

\author{
Katia M. Inoue, ${ }^{a}$ Diogo M. Vidal, ${ }^{b}$ Emir B. Saad, ${ }^{a}$ Camila B. C. Martins ${ }^{a}$ and \\ Paulo H. G. Zarbin ${ }^{\circledR} * a$ \\ ${ }^{a}$ Laboratório de Semioquímicos, Departamento de Química, Universidade Federal do Paraná (UFPR), \\ PO Box 19081, 81531-990 Curitiba-PR, Brazil \\ ${ }^{b}$ Departamento de Química, Universidade Federal de Minas Gerais (UFMG), \\ 31270-901 Belo Horizonte-MG, Brazil
}

\begin{abstract}
The leaf-footed bug, Leptoglossus zonatus (Heteroptera: Coreidae), is mainly found in maize fields in Brazil. In this work, we elucidated and quantified the volatile compounds from nymphs and adults of $L$. zonatus. The defensive compounds produced by nymphs are aldehydes and oxoalkenals, with some compounds showing different proportions between instars. For the first time, 5-ethyl-2(5H)-furanone has been identified as a defensive compound for a species of this family. In adults, the alarm pheromone includes hexanal, 1-hexanol, hexanoic acid, hexyl acetate, and octyl acetate. Males and females produce the same compounds, however, hexanal showed a significant difference between sexes. Gas chromatography (GC) analysis of adult aeration extracts revealed male specific compounds, which attactiveness to females was confirmed through olfactometer bioassays. By using a GC-electroantennographic detector (EAD), it was shown that female antenna presented electrophysiological responses to five components $((Z)$ - $\beta$-ocimene, $(Z, Z)$-allo-ocimene, decanal, $\alpha$-trans-bergamotene, and (E)- $\beta$-farnesene) from male aeration extracts. In this way, we propose that males are responsible for emission of a sex pheromone in this species.
\end{abstract}

Keywords: alarm pheromone, sex pheromone, Coreidae, 5-ethyl-2(5H)-furanone

\section{Introduction}

The leaf footed-bug, Leptoglossus zonatus Dallas (1851) (Heteroptera: Coreidae), is a polyphagous pest that feeds on maize, cotton, blackberry, mango, citrus, beans, guava, peach, soybean and many other crops. ${ }^{1}$ It has been reported in several countries in America, extending from United States to southern Argentina. ${ }^{2}$ In Brazil, both coreid nymphs and adults feed on corn cobs and leaves and can infect plants with fungal yeast that can lead up to $15 \%$ of total production loss. ${ }^{2,3}$

Adults and nymphs of Heteroptera are characterized by the release of irritating volatiles, used as defense against predators and also as alarm pheromones. ${ }^{4}$ In coreid nymphs, the odoriferous compounds are produced in the dorsal abdominal glands (DAGs). In some adults, the DAGs are not present and the metathoracic scent gland (MTG) produces the alarm pheromone instead. ${ }^{5}$ Mixtures of aldehydes, alchools and acetates of six and

*e-mail: pzarbin@ufpr.br eight carbon atoms are commonnly found in the MTG and DAGs of coreids. The most common compounds produced by these glands are $\alpha, \beta$-unsaturated aldehydes and oxo-aldehydes. ${ }^{5,6}$

The amount of defensive compounds produced by adults is frequently larger than the attractant pheromones. One way to avoid the suppression of attractant compounds by the alarm pheromone is to collect the volatiles through aeration of undisturbed insects, ${ }^{7}$ or collect volatiles from individual insects. $^{8}$

Studies have shown that males of Leptoglossus spp. produce specific compounds, such as aromatic compounds and sesquiterpenes. ${ }^{59}$ In Amblypelta lutescens lutescens (Heteroptera: Coreidae), field assays suggested that sesquiterpenes can be envolved as an aggregation pheromone. ${ }^{10}$ However, studies that attempted to work with attractants for coreids have shown attractiveness only to natural volatiles and not to synthetic components in field tests. ${ }^{5,11}$ In this way, research is still needed to confirm the chemical components responsible for the sexual attraction in Coreidae, since a better understanding 
of sexual communication and behavior of Coreids can be a useful tool for sustainable pest management.

Leptoglossus spp. population control on crops can be accomplished through organophosphate pesticides, ${ }^{12}$ compounds that are associated with the increase of cancer risk, dementia and potentially involved with Parkinson's disease. ${ }^{11}$ However, there is little report in the literature about enviromentally-friendly management methods for these insects. ${ }^{12}$ There are studies that report the use of parasitoids of L. zonatus eggs and adults, but with low parasitism percentage in laboratory tests. ${ }^{3}$ As an alternative control method, the sex pheromones are efficient, less harmful to the environment, and relatively inexpensive. ${ }^{13}$ Sex pheromones are typically species-specific and do not affect other insects, such as natural enemies. ${ }^{14}$ Due to the high sensitivity of insects olfaction systems, pheromones can be used at very low concentrations, mainly presenting low toxicity to humans, being considered safe for agricultural purposes. ${ }^{15}$

The present work aimed to analyze L. zonatus DAG compounds that remains in the exuviae of the five nymphal instars and the MTG chemical components of adults. We also intended to investigate the chemical composition and attractiveness of the sex pheromone of L. zonatus.

\section{Experimental}

Insect rearing

In April (2016 and 2017), adults and immatures of $L$. zonatus were manually collected in maize fields (Zea mays) from the Instituto Agronômico do Paraná (IAPAR), in Londrina-PR, Brazil (2321'S, $\left.51^{\circ} 09^{\prime} \mathrm{W}\right)$. The insects were transferred to the Laboratório de Semioquímicos at the Universidade Federal do Paraná (UFPR), where they were separated by stage (adults and immatures) and kept at $25 \pm 2{ }^{\circ} \mathrm{C}, 65 \pm 15 \%$ relative humidity $(\mathrm{RH}), 12: 12 \mathrm{~h}$ light:dark. Insects were reared in plastic cages $(35 \times 20 \times 20 \mathrm{~cm})$ and fed with corn cob (Z. mays), green beans (Phaseolus vulgaris), peanuts (Arachis hypogaea), glossy privet (Ligustrum lucidum) and cherry tomatoes (Solanum lycopersicum var. cerasiforme) with replacement every 3 days. Adults were reared in laboratory for at least 15 days prior bioassays.

\section{Extraction of dorsal abdominal glands (DAGs) contents}

DAGs reservoirs shed with exuviae were collected from the exuviae of the five instars nymphs after ecdysis. ${ }^{16}$ The exuviae extracts were obtained by extraction with $500 \mu \mathrm{L}$ of hexane, and the number of exuviae used on each extraction varied between the insects stage. The exuviae used in the extraction process were collected $\leq 24 \mathrm{~h}$ after the insect ecdysis. Five extracts of ten $1^{\text {st }}$ instar exuviae, five extracts of eight $2^{\text {nd }}$ instar, five extracts of four $3^{\text {rd }}$ instar exuviae, five extracts of two $4^{\text {th }}$ instar exuviae, and five extracts of one $5^{\text {th }}$ instar exuviae were obtained, and stored at $-20{ }^{\circ} \mathrm{C}$ until analysis.

\section{Extraction of metathoracic glands (MTGs) contents}

Adults were killed by freezing and dissected immersed in water. In a Petri dish, each insect was pinned in the prothorax in a dorsal-side-up position and the wings were removed. The lateral margins of the abdomen were cut up to the metathorax, and the dorsal cuticle was removed exposing the viscera that were carefully removed. The glandular complex in the metathorax (composed of the orange reservoir and the lateral accessory glands) was removed, dried with a tissue paper and immersed in $1000 \mu \mathrm{L}$ of double distilled high-performance liquid chromatography (HPLC) grade hexane for $24 \mathrm{~h}$. The extracts were stored at $-20^{\circ} \mathrm{C}$ until analysis. Three MTG's extracts of each sex were analyzed by gas chromatographymass spectrometry (GC-MS). ${ }^{17}$

\section{Collection of volatiles}

One cohort of five males and one cohort of five females were placed in separate glass chambers $(25 \times 9 \mathrm{~cm}$ i.d. $)$ containing slices of corn cob and a continuous $1 \mathrm{~L} \mathrm{~min}^{-1}$ flow of humidified and charcoal-filtered air. The volatiles were collected in a glass trap $(11 \times 3 \mathrm{~mm}$ i.d. $)$ containing $20 \mathrm{mg}$ of HayeSep Q 80-100 mesh (Sigma-Aldrich, Steinheim, Germany). Male and female glass traps were eluted with $400 \mu \mathrm{L}$ of double distilled HPLC grade hexane to collect the volatiles released by each sex and stored at $-20{ }^{\circ} \mathrm{C}$ until analysis. ${ }^{17}$ Extracts from male and female were collected every $24 \mathrm{~h}$ for comparison.

\section{Chemical analysis}

Volatile extracts were analyzed by GC-MS (Shimadzu GC-QP 2010 Plus, Tokyo, Japan) with electron ionization mass detector operating in the electron impact (EI) mode $(70 \mathrm{eV})$ with an RTX-5 capillary column $(30 \mathrm{~m} \times 0.25 \mathrm{~mm}$ i.d. and $0.25 \mu \mathrm{m}$ film thickness; Restek, Bellefonte, PA, USA). Samples were analyzed in splitless mode with injector temperature at $250{ }^{\circ} \mathrm{C}$. The column oven temperature was maintained at $40^{\circ} \mathrm{C}$ for $1 \mathrm{~min}$, raised to $250{ }^{\circ} \mathrm{C}$ at a rate of $7{ }^{\circ} \mathrm{C} \mathrm{min}-1$, and maintained at $250{ }^{\circ} \mathrm{C}$ for $10 \mathrm{~min}$ with helium as carrier gas. 
Infrared spectra were obtained by gas chromatographyFourier transform infrared spectroscopy (GC-FTIR) using a Shimadzu GC-2010 gas chromatograph coupled to a DiscovIR-GC infrared detector $\left(4,000-850 \mathrm{~cm}^{-1}\right.$, resolution of $4 \mathrm{~cm}^{-1}$; Spectra Analysis, Marlborough, MA, USA). The GC was equipped with an EC ${ }^{\text {TM}}-5$ capillary column (Alltech, $30 \mathrm{~m} \times 0.25 \mathrm{~mm} \times 0.25 \mu \mathrm{m}$ film thickness) and helium as the carrier gas. The column oven temperature program was the same used in the GC-MS analysis.

Chiral analysis were performed in a $\beta$-DEX ${ }^{\mathrm{TM}} 325$ capillary column $(30 \mathrm{~m} \times 0.25 \mathrm{~mm} \times 0.25 \mu \mathrm{m}$ i.d.; Supelco, Bellefonte, PA, USA) using a Shimadzu GC-17A gas chromatograph equipped with a flame ionization detector (FID) operated in split mode (1:1). The column oven temperature was maintained at $50{ }^{\circ} \mathrm{C}$ for $1 \mathrm{~min}$, raised to $130{ }^{\circ} \mathrm{C}$ at a rate of $1.5^{\circ} \mathrm{C} \mathrm{min}^{-1}$, raised to $200{ }^{\circ} \mathrm{C}$ at a rate of $10^{\circ} \mathrm{C} \mathrm{min}{ }^{-1}$ and maintained at $200{ }^{\circ} \mathrm{C}$ for 10 min with nitrogen as carrier gas.

Volatile extracts were analyzed in a gas chromatograph (Shimadzu GC2010, Tokyo, Japan) coupled with an electroantennographic detector (Syntech ${ }^{\circledR}$, Hilversum, Netherlands) (GC-EAD) equipped with a DB-5 capillary column $(30 \mathrm{~m} \times 0.25 \mathrm{~mm} \times 0.25 \mu \mathrm{m}$; J\&W Scientific Inc., Palo Alto, USA), operated in split mode $\left(1: 1,250{ }^{\circ} \mathrm{C}\right)$ with nitrogen as the carrier gas. The temperature program started at $50{ }^{\circ} \mathrm{C}(1 \mathrm{~min})$ and subsequently increased at $7{ }^{\circ} \mathrm{C} \mathrm{min}{ }^{-1}$ until $270{ }^{\circ} \mathrm{C}(10 \mathrm{~min})$. The antennae were fixed between the stainless steel electrodes using conductive gel (Signa gel, Parker Laboratories, Inc., Fairfield, NJ, USA). The electroantennogram was recorded on the Syntech GCEAD32 software (version 4.6).

${ }^{1} \mathrm{H}$ and ${ }^{13} \mathrm{C}$ nuclear magnetic resonance (NMR) spectra of the synthetic compounds were recorded on an ARX-200 spectrometer (Bruker, Billerica, USA) on 200 and $50 \mathrm{MHz}$, respectively, as $\mathrm{CDCl}_{3}$ solutions. Chemical shifts are expressed in ppm relative to TMS.

\section{Identification of chemical compounds}

The contents of volatile extracts of $L$. zonatus were identified using the mass spectra analysis and retention index (RI) of each compound and co-injections of volatile extracts with reference standards. (E)-2-Hexenal, (Z)-2-hexenal, and $(E)$-2-octenal were purchased from Acros Organics (Geel, Turnhout, Belgium). (E)-4-Oxo-2-hexenal was donated by Dr K. Chauhan of the USDA-ARS (Beltsville, MD, USA). ${ }^{18}$ 3,7-Dimethyl-1,3,6-octatriene, 2,6-dimethyl2,4,6-octatriene, and decanal were purchased from Aldrich Chemical Company (Milwaukee, Wisconsin, USA). $\alpha$-trans-Bergamotene was obtained through its isolation from the essential oil of Copaifera sp. and (E)- $\beta$-farnesene was isolated from the essential oil of Matricaria recutita. ${ }^{19,20}$ The essential oils were fractionated on a silica gel column $(6 \times 3.5 \mathrm{~cm})$ eluted with hexane.

\section{Microderivatization}

Catalytic hydrogenation with palladium on charcoal $(\mathrm{Pd} / \mathrm{C})$

Exuviae extract in hexane and ca. $0.5 \mathrm{mg}$ of $\mathrm{Pd} / \mathrm{C}(10 \%)$ were added to a glass vial. A rubber balloon filled with hydrogen was attached to the vial, and the reaction was stirred for approximately $2 \mathrm{~h}$. The resulting solution was filtered and analyzed by GC-MS.

\section{Synthesis of 5-ethyl-2(5H)-furanone}

\section{5-Ethyl-3-(phenylselanyl)dihydrofuran-2(3H)-one (II)}

Lithium diisopropylamide (LDA) was prepared by adding an $n$-butyllithium solution $(5.56 \mathrm{~mL}, 10.9 \mathrm{mmol}, 1.96 \mathrm{M}$ in hexane) to a mixture of diisopropylamine $(1.18 \mathrm{~mL}$, $8.39 \mathrm{mmol}$ ) and tetrahydrofuran (THF, $18 \mathrm{~mL}$ ) at $-78^{\circ} \mathrm{C}$. This solution was added dropwise to a stirred solution of $\gamma$-caprolactone $(0.312 \mathrm{~mL} ; 2.8 \mathrm{mmol})$ in THF $(9 \mathrm{~mL})$ and stirred for $75 \mathrm{~min}$ at $-78{ }^{\circ} \mathrm{C}$. A solution of diphenyl diselenide ( $2.36 \mathrm{~g}, 7.55 \mathrm{mmol})$ in THF $(12 \mathrm{~mL})$ containing hexamethylphosphoramide (HMPA, $1.46 \mathrm{~mL}, 8.39 \mathrm{mmol}$ ) was added dropwise to the reaction flask at $-78^{\circ} \mathrm{C}$ over a period of $50 \mathrm{~min}$. The resulting mixture was stirred during $30 \mathrm{~min}$ at $-70{ }^{\circ} \mathrm{C}$ and during $30 \mathrm{~min}$ at $-40^{\circ} \mathrm{C}$. The reaction was quenched by the addition of $\mathrm{HCl}$ solution $\left(0.2 \mathrm{~mol} \mathrm{~L}^{-1}\right)$ until complete neutralization. The reaction was then extracted with ethyl acetate, washed with saturated aqueous solutions of $\mathrm{NaHCO}_{3}$ and brine, dried with $\mathrm{Na}_{2} \mathrm{SO}_{4}$, and concentrated by rotary evaporation under reduced pressure. The crude product was purified by column chromatography over silica gel, eluted with hexane and hexane/ethyl acetate (95:5) to furnish 5-ethyl-3-(phenylseleno)dihydrofuran-2(3H)-one in $87 \%$ yield. ${ }^{21} \mathrm{IR}(\mathrm{ZnSe}) v_{\max } / \mathrm{cm}^{-1} 3056,2969,1765,1580$, 1479, 1439, 1192; ${ }^{1} \mathrm{H}$ NMR $\left(200 \mathrm{MHz}, \mathrm{CDCl}_{3}\right) \delta 0.83-0.97$ (m, 3H), 1.97-1.41 (m, 3H), 2.28-2.77 (m, 1H), 3.93-4.09 (m, $1 \mathrm{H}), 4.22-4.39(\mathrm{~m}, 1 \mathrm{H}), 7.29-7.34(\mathrm{~m}, 3 \mathrm{H}), 7.61-7.68$ (m, 2H); $\left.{ }^{13} \mathrm{C} \mathrm{NMR} \mathrm{(50} \mathrm{MHz,} \mathrm{CDCl}_{3}\right) \delta 175.9,135.4,129.3$, 128.8, 127.1, 80.6, 37.4, 35.8, 28.2, 9.3; MS (EI, $70 \mathrm{eV}$ ): $\mathrm{m} / \mathrm{z}(\%): 270\left(\mathrm{M}^{+}, 85\right), 223(3), 195$ (13), 183 (19), 157 (48), 145 (26), 131 (7), 116 (100), 91 (21), 77 (85), 69 (88), 55 (52), 41 (73).

\section{5-Ethyl-2(5H)-furanone (5)}

Aqueous $\mathrm{H}_{2} \mathrm{O}_{2}(8 \mu \mathrm{L}, 0.1 \mathrm{mmol}, 35 \% \mathrm{~m} / \mathrm{m}$ in water $)$ was added dropwise to $\mathbf{I I}(8.5 \mathrm{mg}, 0.03 \mathrm{mmol})$ in THF $(450 \mu \mathrm{L})$, over $5 \mathrm{~min}$ at $0{ }^{\circ} \mathrm{C}$. The mixture was stirred at room temperature for another $2 \mathrm{~h}$. The reaction was 
quenched with a saturated solution of aqueous $\mathrm{NaHCO}_{3}$ $(0.1 \mathrm{~mL}$, extracted with ethyl ether and concentrated in vacuo to afford 5-ethyl-2(5H)-furanone (5) in 57\% yield. ${ }^{21} \mathrm{IR}(\mathrm{ZnSe}) \mathrm{v}_{\max } / \mathrm{cm}^{-1} 3095,2976,1747,1600,1464$, 1170, 1109, 1012, 962, 904; ${ }^{1} \mathrm{H}$ NMR $\left(200 \mathrm{MHz}, \mathrm{CDCl}_{3}\right)$ $\delta 1.02(\mathrm{t}, 3 \mathrm{H}, J 7.4 \mathrm{~Hz}), 1.66-1.92(\mathrm{~m}, 2 \mathrm{H}), 5.01(\mathrm{~m}, 1 \mathrm{H})$, $6.13(\mathrm{dd}, 1 \mathrm{H}, J 5.7,2.0 \mathrm{~Hz}), 7.45(\mathrm{dd}, 1 \mathrm{H}, J 5.7,1.5 \mathrm{~Hz})$; ${ }^{13} \mathrm{C}$ NMR $\left(50 \mathrm{MHz}, \mathrm{CDCl}_{3}\right) \delta 173.1,155.9,121.8,84.3$, 26.3, 9.0; MS (EI, $70 \mathrm{eV}): m / z(\%): 112\left(\mathrm{M}^{+}, 7\right), 84(15)$, 83 (100), 57 (12), 55 (35).

\section{Olfactometer bioassays}

The behavior of male and female L. zonatus in the presence of the natural male sex pheromone was observed in a Y-olfactometer tube $(4 \mathrm{~cm}$ in diameter, $40 \mathrm{~cm}$ long, $20 \mathrm{~cm}$ long arms) operated at $2 \mathrm{~L} \mathrm{~min}^{-1}$ flow of humidified and charcoal filtrated air. The bioassay was conducted during the photophase at $25 \pm 2.0^{\circ} \mathrm{C}$ and $65 \pm 15 \% \mathrm{RH}$. A piece of filter paper of $2 \mathrm{~cm}^{2}$ loaded with $20 \mu \mathrm{L}$ of extract from males was placed at the extremity of one arm of the tube and the solvent was placed as a control in the extremity of the other arm. The solvent of the solutions loaded to the filter paper was evaporated before using it in the bioassay. Twigs of the host plant (glossy privet) and a piece of corn cob were used as attractant in both treatments. One virgin adult (male or female) was placed in the entrance of the basal tube of the olfactometer and its behavior was observed for $8 \mathrm{~min}$. Twelve individual males and 12 individual females were used in the bioassay and a choice was scored whenever the insect walked towards one of the arms and passed by $5 \mathrm{~cm}$ of the division of the basal tube, staying there for at least $2 \mathrm{~min}$.

The mean amounts of the EAD active compounds present in the natural extract used in the bioassays were $0.35 \pm 0.02 \mathrm{mg}(\mathbf{1 2}, 3,7$-dimethyl-1,3,6-octatriene $)$, $0.13 \pm 0.06 \mathrm{mg}(\mathbf{1 3}, 2,6$-dimethyl-2,4,6-octatriene $)$,
$0.01 \pm 0.00 \mathrm{mg}(\mathbf{1 4}$, decanal $), 1.5 \pm 0.53 \mathrm{mg}(\mathbf{1 5}, \alpha$-transbergamotene) and $0.04 \pm 0.03 \mathrm{mg}(\mathbf{1 6},(E)-\beta$-farnesene $)$ (equivalent to 2 males).

\section{Statistical analysis}

Chromatographic peak area from each compound present in exuviae and MTG extracts were compared using analysis of variance (ANOVA) and the means were compared by Tukey's test (5\%) using the statistical software Minitab 17.22 After this, peak area was transformed to percentage to better visualization of relative amounts of each compound present on extracts. The olfactometer bioassay data was analyzed through binomial test using the statistical program BioEstat 5.0. ${ }^{23}$

\section{Results and Discussion}

DAGs and MTG chemical composition

Chromatograms of the DAGs and MTG extracts (Figures 1 and 2) showed different compounds released by nymphs and adults of $L$. zonatus. Six compounds were present in the DAGs extracts and identified as $(E)$-3-hexenal (1) (RI: 806), (Z)-2-hexenal (2) (RI: 847), (E)-2-hexenal (3) (RI: 853), (E)-4-oxo-2-hexenal (4) (RI: 956), 5-ethyl2(5H)-furanone (5) (RI: 1035), and (E)-2-octenal (6) (RI: 1059). The peak eluting after 4 (Figure 1) refers to 5-ethyl-3H-furan-2-one, known as a degradation product from $(E)$-4-oxo-2-hexenal (4), due to extraction conditions. ${ }^{8}$ All compounds were identified through analysis of mass and infrared spectra, comparisons of the retention indexes and co-injection with synthetic standards.

The major components of the volatiles of nymphs are (E)-4-oxo-2-hexenal (4) and (E)-2-hexenal (3) (Table 1). On the first instar, the production of these compounds

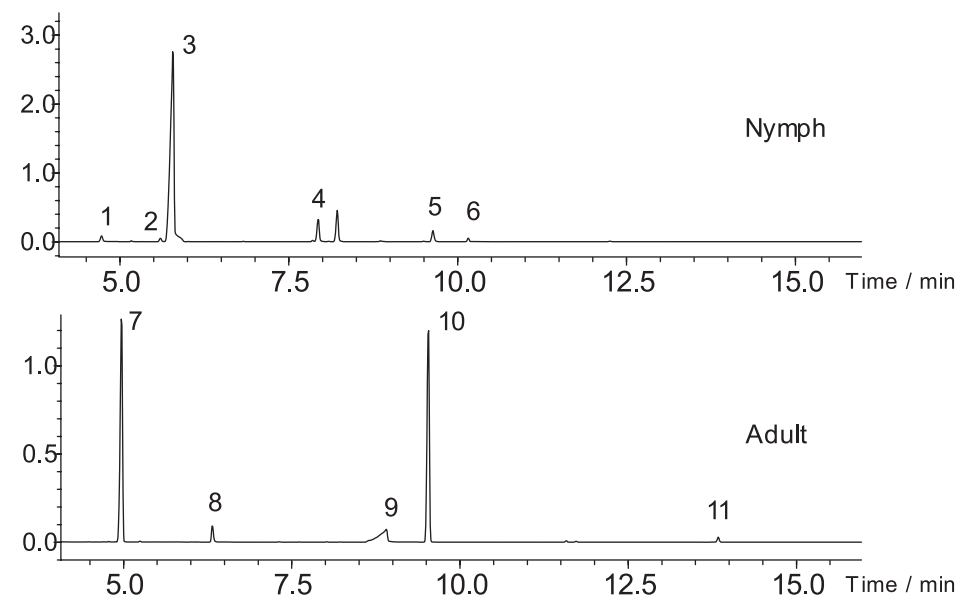

Figure 1. Comparison between the exuvial extracts of Leptoglossus zonatus of the $4^{\text {th }}$ instar and MTG extracts of adults. 


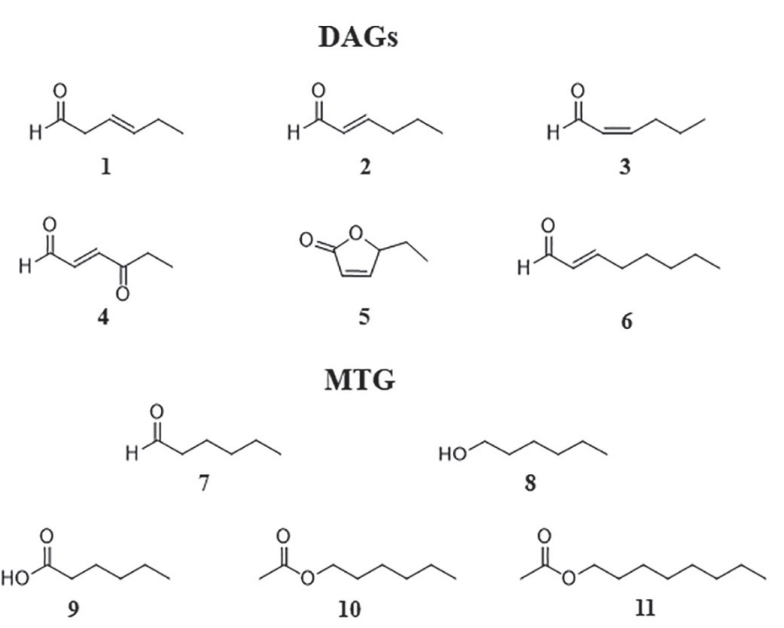

Figure 2. Leptoglossus zonatus defensive compounds identified in the DAGs and alarm pheromone in the MTG.

reaches more than $98 \%$ of the whole extract, with $\mathbf{4}$ as major component. However, $\mathbf{3}$ is produced in highest amount by insects of the second to fifth instar, followed by 4. These compounds are commonly found in other coreid species and in some other families of Heteroptera. ${ }^{5,6}$ They can induce a dispersive behavior between conspecifics, and paralyze or deter many predators, such as mantids. ${ }^{4,24}$ In Thasus neocalifornicus (Coreidae), the presence of Wolbachia microorganisms can interfere positively in the production of $\mathbf{3}$ and $\mathbf{4}$ in nymphs, evidencing a possible symbiotic relationship. ${ }^{25}$

Compounds $\mathbf{4}$ and $\mathbf{5}$ showed very similar mass spectra, but clearly different infrared spectra, as shown in Figure 3. The IR spectrum for 4 (Figure 3a) showed two strong bands at 1686 and $1674 \mathrm{~cm}^{-1}$, related to $\mathrm{C}=\mathrm{O}$ stretching, with the first one as typical from an $\alpha, \beta$-unsaturated aldehyde and the second as related to a ketone. ${ }^{26}$ Through co-injection with the synthetic standard, the compound $\mathbf{4}$ was confirmed as (E)-4-oxo-2-hexenal, a compound commonly found in members of the Coreidae family. ${ }^{6,25}$

The lactone 5-ethyl-2(5H)-furanone was suggested as being compound $\mathbf{5}$ through comparisons of its mass spectra with the NIST database, in addition to infrared data. Compound 5 was purified through fractionation of the extract followed by a catalytic hydrogenation derivatization, revealing one double bond since there was an increase of two mass units on the derivative MS spectrum. The IR spectrum of 5 (Figure $3 b$ ) showed a strong $\mathrm{C}=\mathrm{O}$ stretching band at $1746 \mathrm{~cm}^{-1}$ characteristic of an $\alpha, \beta$-unsaturated lactone. The mass spectrum (Figure $3 d$ ) showed a molecular ion $\left(\mathrm{M}^{+}\right)$at $\mathrm{m} / \mathrm{z} 112$ and a base peak at $\mathrm{m} / \mathrm{z} 83$ due to the loss of the side chain $\left(\mathrm{C}_{2} \mathrm{H}_{5}^{+}\right)$.

To confirm its structure, the lactone $\mathbf{5}$ was synthesized and obtained from a mixture of stereoisomers as showed in Scheme 1 . The selenylation reaction of the $\gamma$-caprolactone I with diphenyl diselenide resulted on II in $87 \%$ yield. Compound $\mathbf{5}$ was obtained through selenoxyde elimination from II, with $\mathrm{H}_{2} \mathrm{O}_{2}$, in $57 \%$ yield. The structure of $\mathbf{5}$ was confirmed after co-injection of the natural extract and the synthetic lactone.

Enantioselective gas chromatography was used to determine the absolute configuration of the lactone through comparison of the natural extract, the racemic mixture and an enantiopure synthetic standard (Figure S7, Supplementary Information (SI) section) using $\beta$-cyclodextrin based chiral capillary column ( $\beta$-DEX ${ }^{\mathrm{TM}} 325$, Sigma-Aldrich, St. Louis, USA). Synthetic racemic 5 was resolved and retention times compared with $(S)$-5-ethyl-2(5H)-furanone $(S-5)$, obtained when $(S)$ - $\gamma$-caprolactone was used as starting material and with the natural compound, showing that it occurs as a racemate.

The lactone $\mathbf{5}$ is commonly found in plant volatiles such as tomato, soybean and guava. ${ }^{27,28}$ It was also identified as a defensive compound in species of Pentatomidae (Graphosoma lineatum and Halyomorpha halys), a specie of Blattidae (Eurycotis floridana) and species of Pyrrhocoridae..$^{29,30}$

MTG extracts from adults showed five compounds which were identified through retention indexes (RI) and mass spectra: hexanal (7, RI: 807), 1-hexanol (8, RI: 865), hexanoic acid (9, RI: 989), hexyl acetate (10, RI: 1013) and octyl acetate (11, RI: 1210). MS spectrum

Table 1. Relative abundance (mean \pm standard deviation) of compounds present in Leptoglossus zonatus exuvial extracts from first to fifth-instars using the Tukey's test $(p<0.05)$

\begin{tabular}{lccccc}
\hline \multirow{2}{*}{ Compound } & \multicolumn{5}{c}{ Relative abundance / \% } \\
\cline { 2 - 6 } & $1^{\text {st }}$ instar & $2^{\text {nd }}$ instar & $3^{\text {rd }}$ instar & $4^{\text {th }}$ instar & $5^{\text {th }}$ instar \\
\hline (E)-3-Hexenal (1) & $0.6 \pm 0.1 \mathrm{a}$ & $2.3 \pm 1.6 \mathrm{~b}$ & $1.3 \pm 0.2 \mathrm{ab}$ & $0.9 \pm 0.4 \mathrm{ab}$ & $1.6 \pm 0.3 \mathrm{ab}$ \\
(Z)-2-Hexenal (2) & $0.6 \pm 0.1 \mathrm{a}$ & $1.2 \pm 0.9 \mathrm{a}$ & $3.3 \pm 5.8 \mathrm{a}$ & $0.6 \pm 0.2 \mathrm{a}$ & $0.8 \pm 0.1 \mathrm{a}$ \\
(E)-2-Hexenal (3) & $42.9 \pm 3.7 \mathrm{a}$ & $77.0 \pm 5.1 \mathrm{~b}$ & $67.8 \pm 5.5 \mathrm{~b}$ & $71.4 \pm 7.2 \mathrm{~b}$ & $72.1 \pm 7.03 \mathrm{~b}$ \\
$(E)$-4-Oxo-2-hexenal (4) & $56.2 \pm 4.4 \mathrm{a}$ & $14.6 \pm 5.0 \mathrm{~b}$ & $25.3 \pm 7.4 \mathrm{~b}$ & $22.9 \pm 9.6 \mathrm{~b}$ & $24.2 \pm 5.7 \mathrm{~b}$ \\
5-Ethyl-2(5H)-furanone (5) & Tr b & $1.6 \pm 0.7 \mathrm{ab}$ & $1.6 \pm 1.4 \mathrm{ab}$ & $2.2 \pm 1.7 \mathrm{a}$ & $0.7 \pm 0.5 \mathrm{ab}$ \\
$(E)$-2-Octenal (6) & Tr c & $0.9 \pm 0.1 \mathrm{a}$ & $0.9 \pm 0.1 \mathrm{a}$ & $0.9 \pm 0.3 \mathrm{a}$ & $0.5 \pm 0.4 \mathrm{~b}$ \\
\hline
\end{tabular}

Tr: relative abundance $<0.5$ were not considered. Different letters on each line indicates statistical difference. 

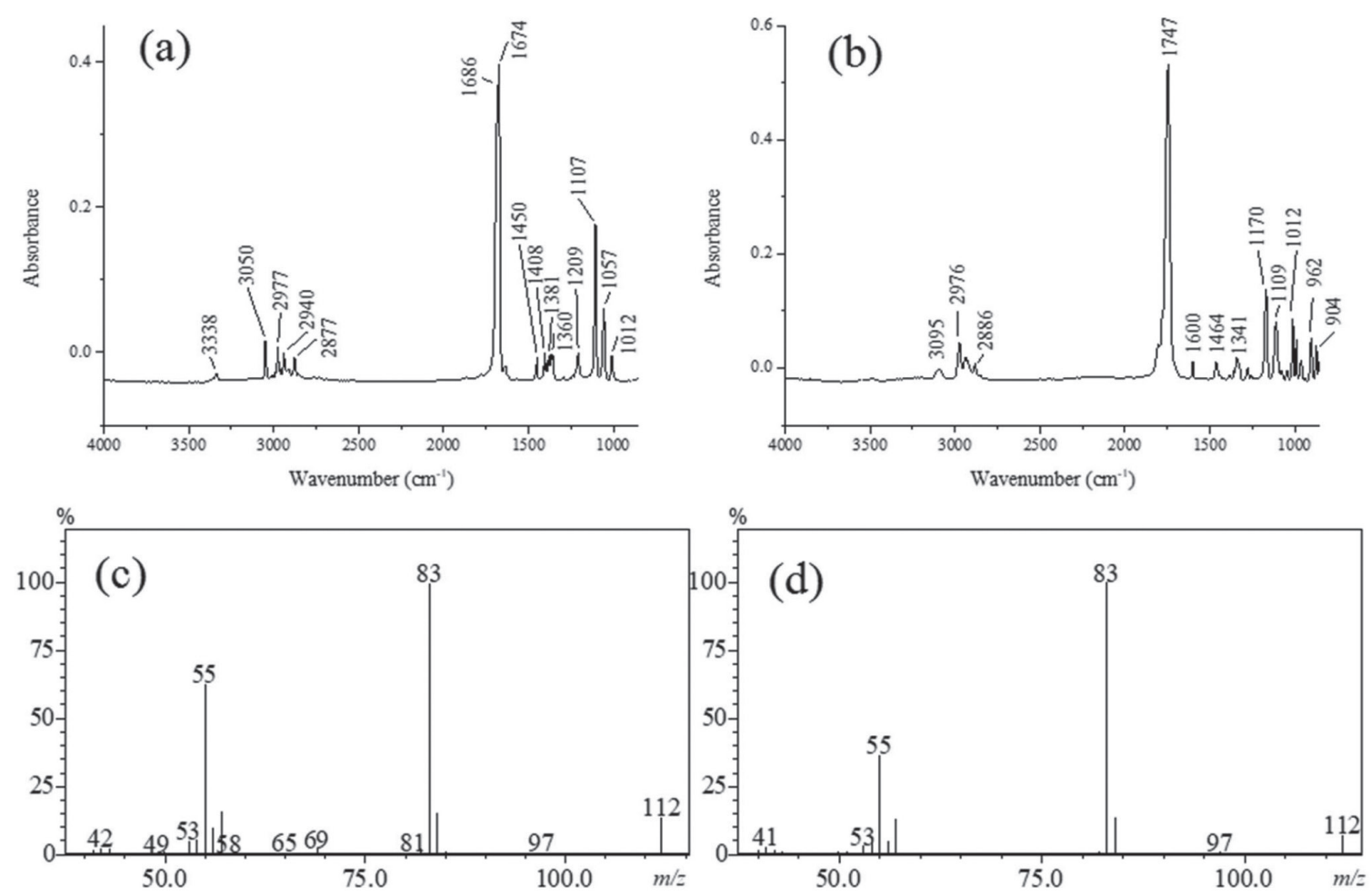

Figure 3. Infrared (ZnSe, GC-FTIR) of compounds (a) 4 and (b) 5; and mass spectra (GC-MS) of (c) 4 and (d) 5 present in the dorsal abdominal glands of Leptoglossus zonatus.

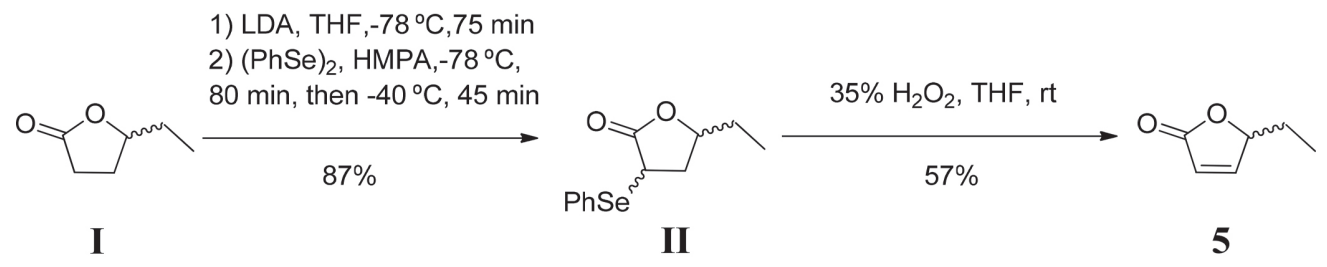

Scheme 1. Synthesis of 5-ethyl-2(5H)-furanone (5).

from hexanal and hexanoic acid (Figures S13 and S15a, SI section) showed McLafferty rearrangements leading to the base peak $m / z 44$ for $\mathbf{7}$ and 60 for $\mathbf{9}$. The structure of the primary alcohol $\mathbf{8}$ was proposed due to the loss of water with elimination of ethylene leading to the presence of the base peak $m / z 56$ (Figure S14a, SI section). Esters 10 and 11 were suggested due to the fragment $m / z 61$, corresponding to the rearrangement of two hydrogens leading to $\left[\mathrm{CH}_{2} \mathrm{C}(\mathrm{OH})\left(\mathrm{OH}_{2}\right)\right]^{+}$(Figures S16a and S17a, SI section). GC-FTIR analyses were performed and spectra showed different characteristic band absorptions of $\mathrm{C}=\mathrm{O}$ stretching: at $1720 \mathrm{~cm}^{-1}$ (aldehyde); at $1701 \mathrm{~cm}^{-1}$ (carboxylic acid); and at $1740 \mathrm{~cm}^{-1}$ (ester) (Figures S13b, S15b, and S16b, SI section). The broad and intense band at $3284 \mathrm{~cm}^{-1}$ indicated an alcohol. The $\mathrm{C}-\mathrm{C}-\mathrm{O}$ asymmetric stretch of primary alcohols appears at $1060 \mathrm{~cm}^{-1}$ (Figure S14b, SI section).

The most abundant compounds found in adults of L. zonatus MTG are $\mathbf{7}$ and $\mathbf{1 0}$ (Table 2), with males producing higher amounts of hexanal when compared with
Table 2. Relative abundance (mean \pm standard deviation) of the compounds present in Leptoglossus zonatus MTG extracts using the Tukey's test $(p<0.05)$

\begin{tabular}{lcc}
\hline \multirow{2}{*}{ Compound } & \multicolumn{2}{c}{ Relative abundance / \% } \\
\cline { 2 - 3 } & Male & Female \\
\hline Hexanal (7) & $52.5 \pm 1.0 \mathrm{a}$ & $38.7 \pm 8.0 \mathrm{~b}$ \\
1-Hexanol (8) & $3.1 \pm 2.7$ & $5.1 \pm 1.1$ \\
Hexanoic acid (9) & $6.7 \pm 10.4$ & $13.2 \pm 3.0$ \\
Hexyl acetate (10) & $36.9 \pm 13.9$ & $41.8 \pm 5.7$ \\
Octyl acetate (11) & $0.9 \pm 0.3$ & $1.2 \pm 0.3$ \\
\hline
\end{tabular}

Different letters on each line indicates statistical difference.

females. Leal et al. ${ }^{4}$ identified most of these compounds for L. zonatus, except octyl acetate (11). However, the relative abundance of the compounds differs from our data due to the use of a different extraction methodology, immersing the insects in hexane during $3 \mathrm{~min}^{4,31}$ In this work, the compounds were extracted directly from the pheromone- 


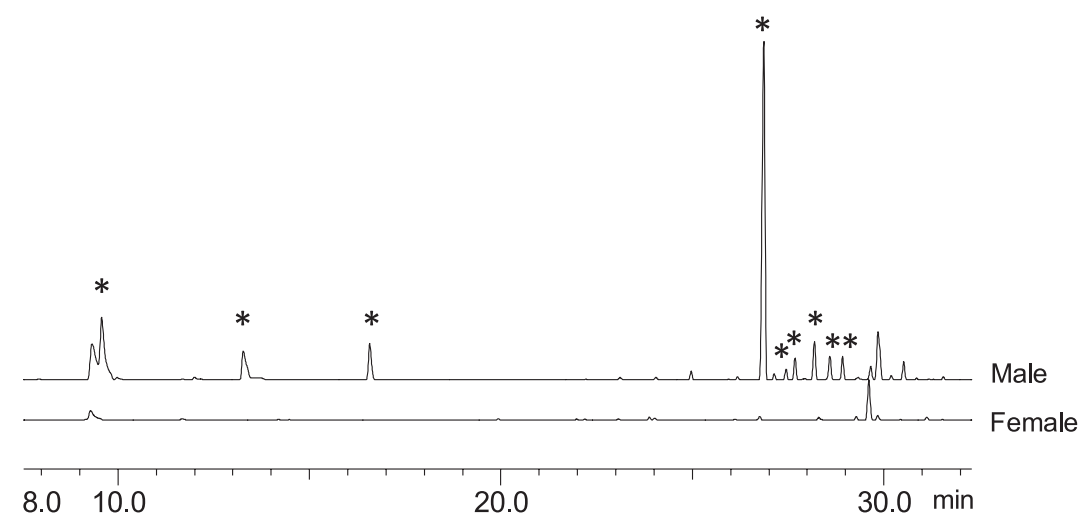

Figure 4. GC analyses of aeration extracts from males and females Leptoglossus zonatus. Male specific compounds are highlighted.

producing glands. The components identified in L. zonatus MTG are also found in other species of coreids as alarm pheromone, not being specie-specific. In addition, the components of the DAGs and the MTG are completely different in Coreidae. ${ }^{6,24}$

Quantification and production of sexual volatiles by Leptoglossus zonatus

Analysis of aeration extracts from L. zonatus showed nine male-specific compounds (Figure 4). Y-Olfactometer bioassays (Figure 5), employing the extract from males, suggested that these compounds are a sex pheromone of this species, once that it was bioactive only to females $(p=0.0012)$.

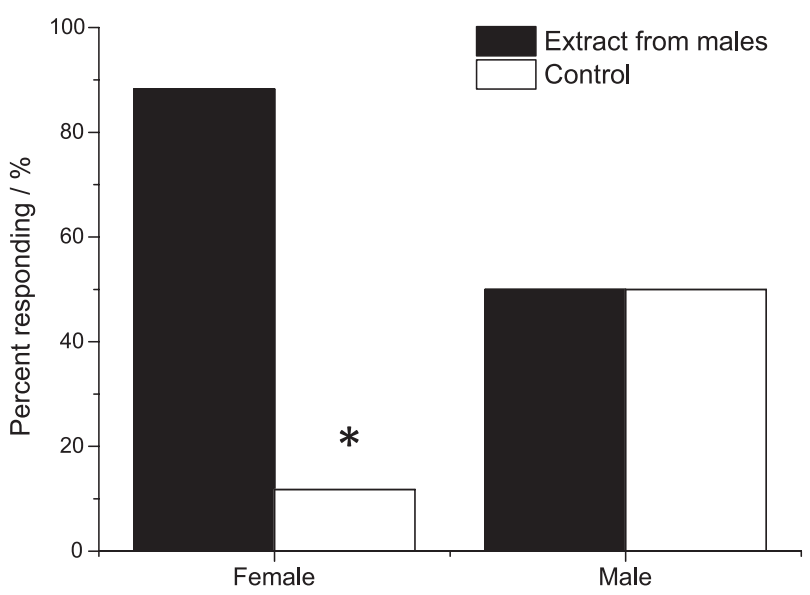

Figure 5. Behavioral responses of females $(\mathrm{n}=17)$ and males $(\mathrm{n}=14)$ Leptoglossus zonatus to aeration extracts from males in a Y-olfactometer using the binomial test $(* p<0.05)$.

The attractiveness of the male-specific pheromone is observed when using the combination of extract from males and parts of the host plants in the bioassays. The volatiles of the host plant can enhance the attractiveness of the sex pheromone because it indicates a good place for oviposition. ${ }^{32}$ The presence of the host plant has also been reported to improve pheromonal attractiveness of species of Coleoptera and Diptera. ${ }^{33,34}$

GC-EAD analysis of female antennae showed active responses to five different compounds present in L. zonatus extract from males (Figure 6). EAD active compounds (13-17) were identified through GC-MS, GCFTIR, retention indexes and co-injection with authentic standards. The mean amounts of compounds 13-17 emitted per insect in $24 \mathrm{~h}$ were $0.18 \pm 0.08 \mathrm{mg}$ (12), $0.06 \pm 0.01 \mathrm{mg}(\mathbf{1 3}), 0.02 \pm 0.04 \mathrm{mg}(\mathbf{1 4}), 0.87 \pm 0.28 \mathrm{mg}$ (15) and $0.02 \pm 0.02 \mathrm{mg}(\mathbf{1 6})$.

MS spectra of compounds $\mathbf{1 2}$ and $\mathbf{1 3}$ (Figures S18a and S19a, SI section) suggested their identity as monoterpenes. MS spectrum obtained from 12 suggested a 3,7-dimethyl1,3,6-octatriene structure. Retention index (1033) and GC-FTIR spectrum (Figure S18b, SI section) allowed the determination of the stereochemistry at $\mathrm{C} 3$ as cis, suggesting 12 as (Z)- $\beta$-ocimene, with a fingerprint identical to previously reported spectra. ${ }^{35}$ Band positions and relative intensity profiles of the two $\mathrm{C}=\mathrm{C}$ stretch bands in the $1600 \mathrm{~cm}^{-1}$ region were useful for determination of the configuration at $\mathrm{C} 3\left(1593\right.$ and $\left.1647 \mathrm{~cm}^{-1}\right)$, with the relative intensity of the higher frequency band being weaker. Out of phase $=\mathrm{CH}_{2}$ stretch $\left(3091 \mathrm{~cm}^{-1}\right)$, trans $\mathrm{CH}$ wag $\left(987 \mathrm{~cm}^{-1}\right)$, and $=\mathrm{CH}$ wag $\left(900 \mathrm{~cm}^{-1}\right)$ bands, confirmed the presence of the terminal double bond at $\mathrm{C}$ 1. Compound $\mathbf{1 2}$ was confirmed as $(Z)$ - $\beta$-ocimene after comparison with analytical data obtained from a reference compound.

Mass spectrum (Figure S19a, SI section) and retention index (1123) obtained for compound $\mathbf{1 3}$ suggested its structure to be related to 2,6-dimethyl-2,4,6-octatriene. IR spectrum showed a $\mathrm{C}-\mathrm{H}$ stretch band at $3043 \mathrm{~cm}^{-1}$ confirming a structure with only internal double bonds (Figure S19b, SI section). The C-H bending stretch $\left(1085 \mathrm{~cm}^{-1}\right)$ suggested the stereochemistry at $\mathrm{C} 4$ and $\mathrm{C} 6$ as cis-cis or trans-trans. Through comparison of previously reported spectra, bands intensities at 1270 and $1238 \mathrm{~cm}^{-1}$ (on plane $\mathrm{C}-\mathrm{H}$ stretches) confirmed the stereochemistry 

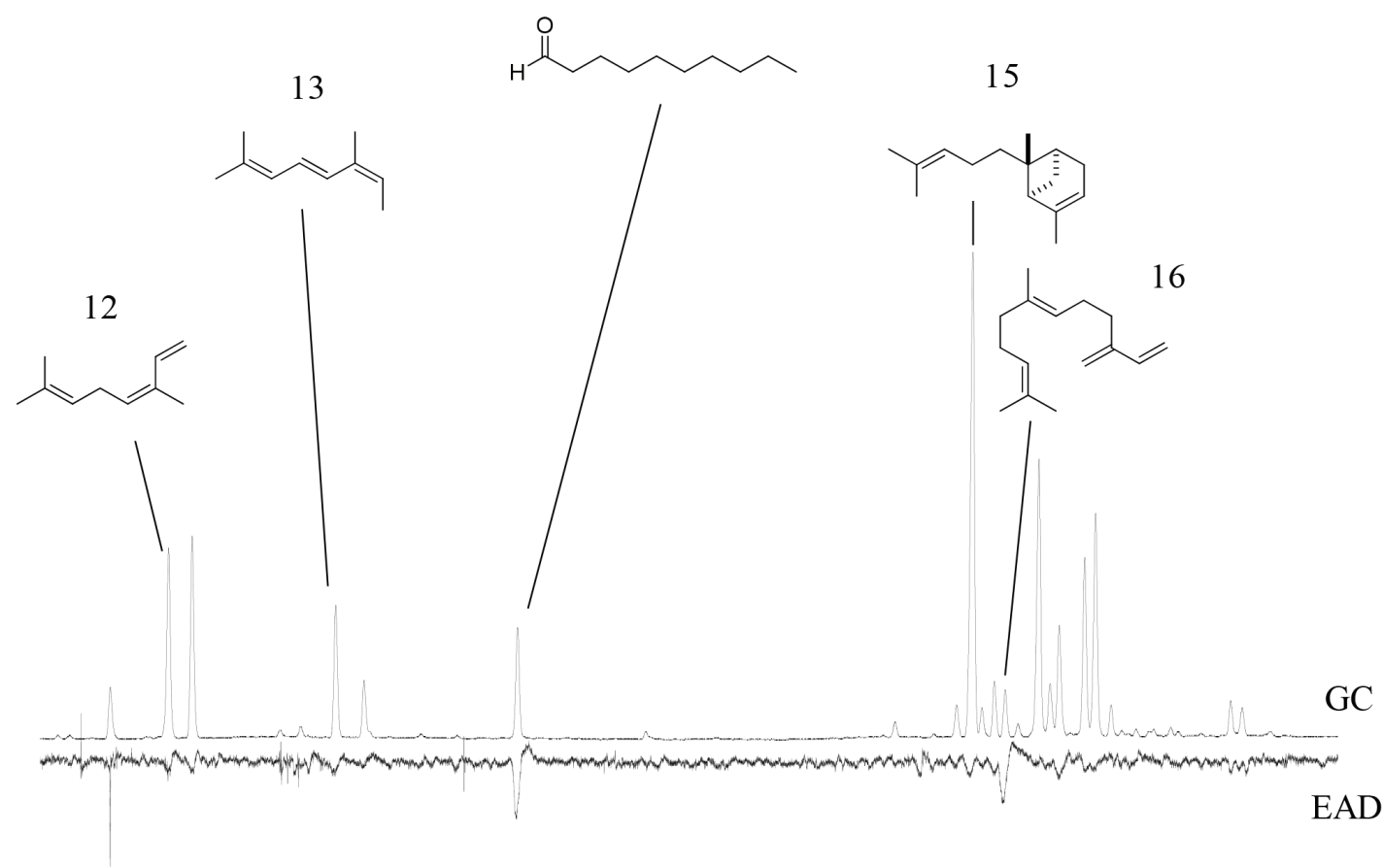

$\mathrm{GC}$

Figure 6. Responses of female Leptoglossus zonatus antenna to the extract from males in GC-EAD analysis.

at $\mathrm{C} 4$ and $\mathrm{C} 6$ as cis-cis. ${ }^{36}$ Moreover, the retention index of the isomer trans-trans is higher than the compound $\mathbf{1 3}$ $\left(\mathrm{RI}_{\text {trans-trans: }}: 1140 ; \mathrm{RI}_{13}:\right.$ 1123). Compound $\mathbf{1 3}$ was identified as Z,Z-allo-ocimene.

IR spectrum from 14 (RI: 1204) presented a strong $\mathrm{C}=\mathrm{O}$ stretching absorption at $1715 \mathrm{~cm}^{-1}$ and a $\mathrm{C}-\mathrm{H}$ stretching absorption at $2753 \mathrm{~cm}^{-1}$, typical for aldehydes (Figure S20, SI section). Moreover, MS spectrum showed typical fragments for long chain aldehydes, with base peak at $\mathrm{m} / \mathrm{z} 57$, and the molecular ion at $156 \mathrm{~m} / \mathrm{z}$, suggesting its structure as decanal.

The compounds $\mathbf{1 5}$ and $\mathbf{1 6}$ presented $\mathrm{M}^{+}$at $m / z$ 204, with MS spectra related to sesquiterpenes. Comparison of these compounds with the NIST mass spectral library suggested $\alpha$-trans-bergamotene (RI: 1438 ) to compound $\mathbf{1 5}$ and (E)- $\beta$-farnesene (RI: 1458 ) to compound 16. IR spectrum for compound 15 showed an absorption band in $3027 \mathrm{~cm}^{-1}$ (C-H stretch) (Figure S21b, SI section) revealing the presence of internal trisubstituted double bonds. On the other hand, IR spectrum obtained from 17 (Figure S22b, SI section), suggested an (E)- $\beta$-type compound due to the presence of the bands at $3089 \mathrm{~cm}^{-1}$, corresponding to out of phase $=\mathrm{CH}_{2}$ stretch and at $1109 \mathrm{~cm}^{-1}\left(-\mathrm{C}\left(\mathrm{CH}_{3}\right)=\mathrm{CH}\right)$, useful to determinate the stereochemistry at $\mathrm{C} 3$ as trans. These compounds were identified through comparisons of mass and infrared spectra and co-injection of isolated reference compounds from essential oils of Copaifera sp. and Matricaria recutita. ${ }^{37,38}$
A wide variety of structures are found as sex pheromones in Pentatomidae, such as cis and trans-(Z)- $\alpha$-bisabolene epoxides in Nezara viridula and $(R)$-15-hexadecanolide for Piezodorus hybneri. ${ }^{39,40}$ In Coreidae, the sex specific compounds do not present structural patterns. Two specific male compounds were identified in the ventral abdominal gland of Pachylis laticornis as (E)-2-hexenyl tiglate and (E)-2-hexenyl (E)-2-hexenoate. ${ }^{41}$ In Phthia picta the sex pheromone is the hydrocarbon 5,9,17-trimethylhenicosane. ${ }^{42}$ Monoterpenes and sesquiterpenes were found in male volatiles of Amblypelta lutescens lutescens $((-)-(3 R)-(E)$-nerolidol) and Leptoglossus phyllopus $((E)$-nerolidol $){ }^{9}$

\section{Conclusions}

In summary, the defensive compounds and the alarm pheromone of $L$. zonatus were described. It is the first time that 5-ethyl-2(5H)-furanone was identified as a defensive compound of nymphs in this family. In addition, an evidence for existence of male sex pheromone was found. Aeration extracts from $L$. zonatus included five male-specific and EAD active compounds that have high probability of being related to the sex pheromone of the species. Further investigation is underway in order to evaluate the effect of these compounds in field experiments and the influence of the host plant in the sexual communication of this species. 


\section{Supplementary Information}

Supplementary information (GC-MS, GC-FTIR, NMR) are available free of charge at http://jbcs.sbq.org.br as PDF file.

\section{Acknowledgments}

The authors would like to thank Dr Daiane Szczerbowski and MSc Samara Mendes for contributions to this manuscript and Dr Rodolfo Bianco for capture and donation of insects. This reasearch was supported by INCT Semioquímicos na Agricultura, CNPq and CAPES.

\section{References}

1. Xiao, Y. F.; Fadamiro, H. Y.; J. Appl. Entomol. 2010, 134, 694.

2. Matrangolo, W.; Waquil, J.; An. Soc. Entomol. Bras. 1994, 23, 419.

3. Marchiori, C. H.; Cienc. Rural 2003, 33, 767.

4. Leal, W. S.; Panizzi, A. R.; Niva, C. C.; J. Chem. Ecol. 1994, $20,1209$.

5. Aldrich, J. R.; Annu. Rev. Entomol. 1988, 33, 211.

6. Noge, K.; Kakuda, T.; Abe, M.; Tamogami, S.; J. Chem. Ecol. 2015, 41, 757.

7. Millar, J. G.; Top. Curr. Chem. 2005, 240, 37.

8. Fountain, M.; Jåstad, G.; Hall, D.; Douglas, P.; Farman, D.; Cross, J.; J. Chem. Ecol. 2014, 40, 71.

9. Aldrich, J. R.; Waite, G. K.; Moore, C.; Payne, J. A.; Lusby, W. R.; Kochansky, J. P.; J. Chem. Ecol. 1993, 19, 2767.

10. Khrimian, A.; Fay, H. A. C.; Guzman, F.; Chauhan, K.; Moore, C.; Aldrich, J. R.; Psyche 2012, ID 536149.

11. Paul, K. C.; Sinsheimer, J. S.; Cockburn, M.; Bronstein, J. M.; Bordelon, Y.; Ritz, B.; Environ. Int. 2017, 107, 75.

12. Gallo, D.; Nakano, O.; Wiendel, F. M.; Silveira Neto, S.; Carvalho, R. P. L.; de Batista, G. C.; Berti Filho, E.; Para, J. R. P.; Zucchi, R. A.; Alves, S. B.; Vendramin, J. D.; Manual de Entomologia Agrícola; FEALQ: Piracicaba, 2002.

13. Stenberg, J. A.; Trends Plant Sci. 2017, 22, 759.

14. Raguso, R. A.; Agrawal, A. A.; Douglas, A. E.; Jander, G.; Kessler, A.; Poveda, K.; Thaler, J. S.; Ecology 2015, 96, 617.

15. Witzgall, P.; Kirsch, P.; Cork, A.; J. Chem. Ecol. 2010, 36, 80.

16. Borges, M.; Aldrich, J. R.; Experientia 1992, 48, 893.

17. Fávaro, C. F.; Santos, T. B.; Zarbin, P. H. G.; J. Chem. Ecol. 2012, 38, 1124.

18. Feldlaufer, M. F.; Domingue, M. J.; Chauhan, K. R.; Aldrich, J. R.; J. Med. Entomol. 2010, 47, 140.

19. Bardají, D. K. R.; da Silva, J. J. M.; Bianchi, T. C.; Eugênio, D. S.; de Oliveira, P. F.; Leandro, L. F.; Rogez, H. L. G.; Venezianni, R. C. S.; Ambrosio, S. R.; Tavares, D. C.; Bastos, J. K.; Martins, C. H. G.; Anaerobe 2016, 40, 18.
20. Mekonnen, A.; Yitayew, B.; Tesema, A.; Taddese, S.; Int. J. Microbiol. 2016, 2016, 8.

21. Tamura, R.; Chen, Y.; Shinozaki, M.; Arao, K.; Wang, L.; Tang, W.; Hirano, S.; Ogura, H.; Mitsui, T.; Taketani, S.; Ando, M.; Kataoka, T.; Bioorg. Med. Chem. Lett. 2012, 22, 207.

22. Minitab Inc.; Minitab 17 Statistical Software; State College, PA, USA, 2010.

23. Ayres, M.; Ayres, M. J.; Ayres, D. L.; Santos, A. S.; BioEstat 5.0; Sociedade Civil Mamirauá: Belém, PA, Brazil, 2007.

24. Prudic, K. L.; Noge, K.; Becerra, J. X.; J. Chem. Ecol. 2008 , $34,734$.

25. Becerra, J. X.; Venable, G. X.; Saeidi, V.; J. Chem. Ecol. 2015, $41,593$.

26. Silverstein, R. M.; Webster, F. X.; Kiemle, D. J.; Spectrometric Identification of Organic Compounds, $7^{\text {th }}$ ed.; John Wiley \& Sons: Hoboken, 2005.

27. Cai, L.; Koziel, J.; O’Neal, M.; Chromatography 2015, 2, 265.

28. Farneti, B.; Alarcón, A. A.; Papasotiriou, F. G.; Samudrala, D.; Cristescu, S. M.; Costa, G.; Harren, F. J. M.; Woltering, E. J.; Food Bioprocess Technol. 2015, 8, 1442.

29. Farine, J. P.; Everaerts, C.; Brossut, R.; Le Quére, J. L.; Biochem. Syst. Ecol. 1993, 21, 363.

30. Solomon, D.; Dutcher, D.; Raymond, T.; J. Air Waste Manage. Assoc. 2013, 63, 1264.

31. Zarbin, P. H. G.; Ferreira, J. T. B.; Leal, W. S.; Quim. Nova 1999, 22, 263.

32. Blatt, S. E.; Borden, J. H.; Can. Entomol. 1996, 128, 777.

33. Yasui, H.; Fujiwara-Tsujii, N.; Sci. Rep. 2016, 6, 29526.

34. Bachmann, G. E.; Segura, D. F.; Devescovi, F.; Juárez, M. L.; Ruiz, M. J.; Vera, M. T.; Cladera, J. L.; Teal, P. E. A.; Fernández, P. C.; PLoS One 2015, 10, e0124250.

35. Svatoš, A.; Attygalle, A. B.; Anal. Chem. 1997, 69, 1827.

36. Mitzner, B. M.; Theimer, E. T.; Freeman, S. K.; Appl. Spectrosc. 1965, 19, 169.

37. Ziech, R. E.; Farias, L. D.; Balzan, C.; Ziech, M. F.; Heinzmann, B. M.; Lámeira, O. A.; de Vargas, A. C.; Pesq. Vet. Bras. 2013, 33, 909.

38. Heuskin, S.; Godin, B.; Leroy, P.; Capella, Q.; Wathelet, J. P.; Verheggen, F.; Haubruge, E.; Lognay, G.; J. Chromatogr. A 2009, 1216, 2768.

39. Brézot, P.; Malosse, C.; Mori, K.; Renou, M.; J. Chem. Ecol. 1994, 20, 3133.

40. Leal, W. S.; Kuwahara, S.; Ono, M.; Meinwald, J.; J. Chem. Ecol. 1998, 24, 1817.

41. Aldrich, J. R.; Kochansky, J. P.; Lusby, W. R.; Dutky, S. R.; J. Chem. Ecol. 1982, 8, 1369.

42. Soldi, R. A.; Rodrigues, M. A. C. M.; Aldrich, J. R.; Zarbin, P. H. G.; J. Chem. Ecol. 2012, 38, 814.

Submitted: May 9, 2018 Pubished online: December 10, 2018 